\title{
Retrocondylar Far-Lateral Approach for Resection of a Craniocervical Junction Hemangioblastoma
}

\author{
Alexander X. Tai ${ }^{1}$ Kathleen Knudson ${ }^{2}$ Walter C. Jean ${ }^{2(1)}$ \\ ${ }^{1}$ Department of Neurosurgery, Georgetown University, Washington, \\ District of Columbia, United States \\ 2 Department of Neurosurgery, George Washington University, \\ Address for correspondence Alexander X. Tai, MD, Department of \\ Neurosurgery, Georgetown University Hospital, 3800 Reservoir Road \\ Washington, District of Columbia, United States \\ Northwest, 7th Floor PHC, Washington, DC 20007, United States \\ (e-mail: Axt2@georgetown.edu).
}

J Neurol Surg B 2019;80(suppl S4):S349-S351.

\begin{abstract}
\section{Keywords}

- far-lateral approach

- craniocervical junction

- hemangioblastoma

- retrocondylar

We present a case in which a retrocondylar far-lateral approach was utilized to resect a hemangioblastoma at the craniocervical junction. The patient was a 33-year-old man presenting with 2 months of symptoms referable to compression at the craniocervical junction (i.e., dizziness and gait instability). Though neurologically intact on exam, his imaging demonstrated a highly vascular cystic lesion dorsolateral to the medulla on the left consistent with a hemangioblastoma. Virtual reality software was critical to visualize the patient's lesion in relationship to the vertebral artery and draining vein (-Fig. 1). A far-lateral retrocondylar suboccipital craniectomy with a $\mathrm{C} 1$ hemilamiectomy permitted resection of this lesion. The operative strategy was to address the lesion similar to an arteriovenous malformation by detaching the lesion from its arterial feeders first, and then addressing the lesion's draining vein (-Fig. 2). Postoperative imaging demonstrated a gross-total resection and the patient had an uncomplicated postoperative course. This case demonstrates not only the lateral reach of a retrocondylar far-lateral approach; but also, clearly demonstrates an effective dissection strategy when approaching a hemangioblastoma.

The link to the video can be found at: https://youtu.be/MOszMOdhjfE.
\end{abstract}

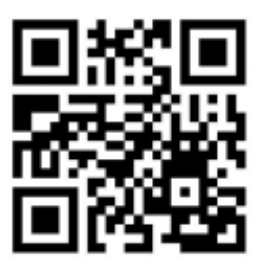

received

February 28, 2019

accepted

August 25, 2019

published online

October 22, 2019

www.thieme.com/skullbasevideos

www.thieme.com/jnlsbvideos

DOI https://doi.org/

10.1055/s-0039-1698821. ISSN 2193-6331.
๑) 2019 Georg Thieme Verlag KG
Stuttgart · New York

License terms

(c) $(1) \ominus$ (\$) 


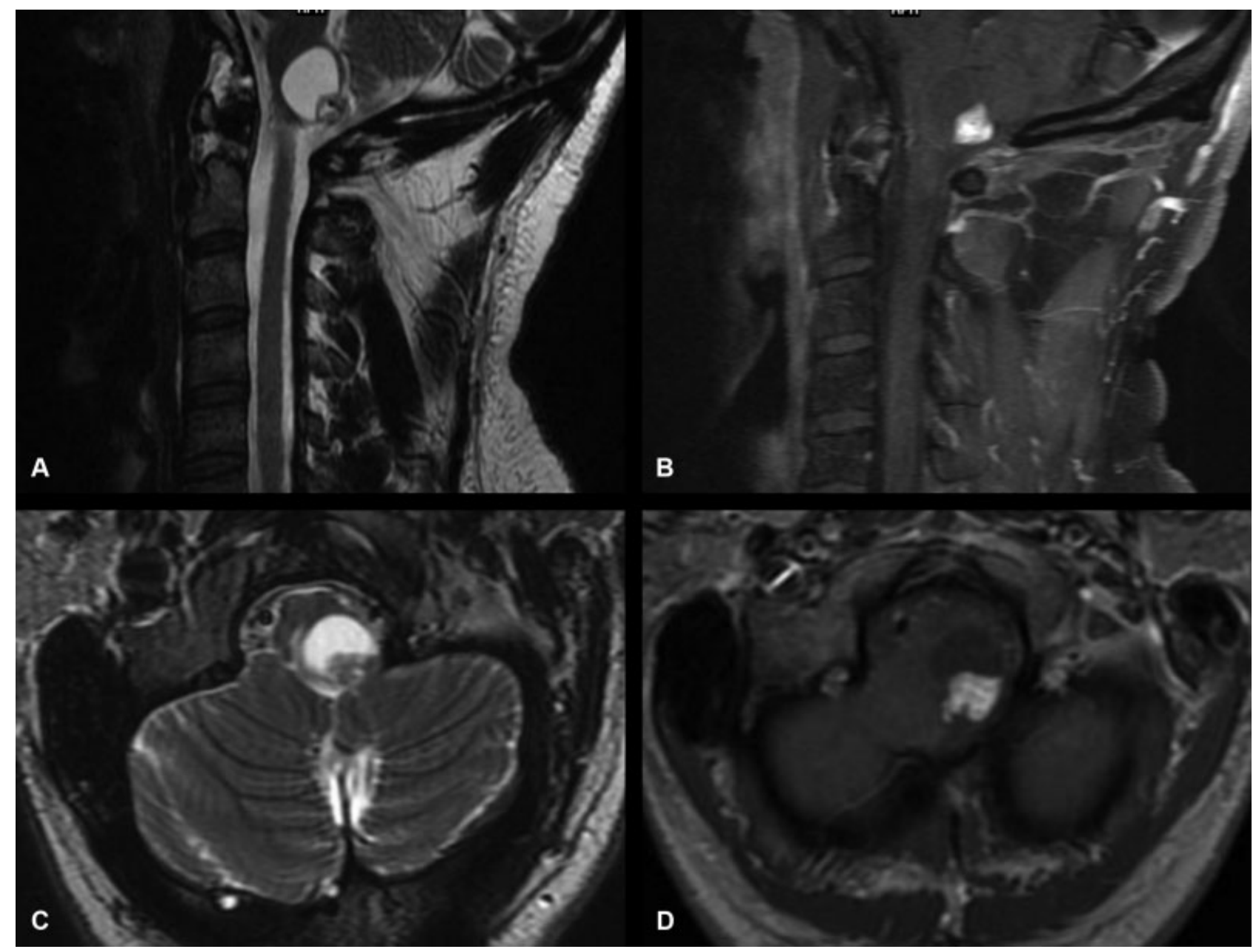

Fig. 1 Preoperative imaging of a craniocervical hemangioblastoma. (A, C) T2-weighted axial and sagittal MRI imaging demonstrates a cystic lesion dorsolateral to the medulla causing medullary compression. (B, D) T1-weighted postcontrast sagittal and axial MRI imaging demonstrates the cystic lesion has a peripherally enhancing mural nodule. MRI, magnetic resonance imaging. 

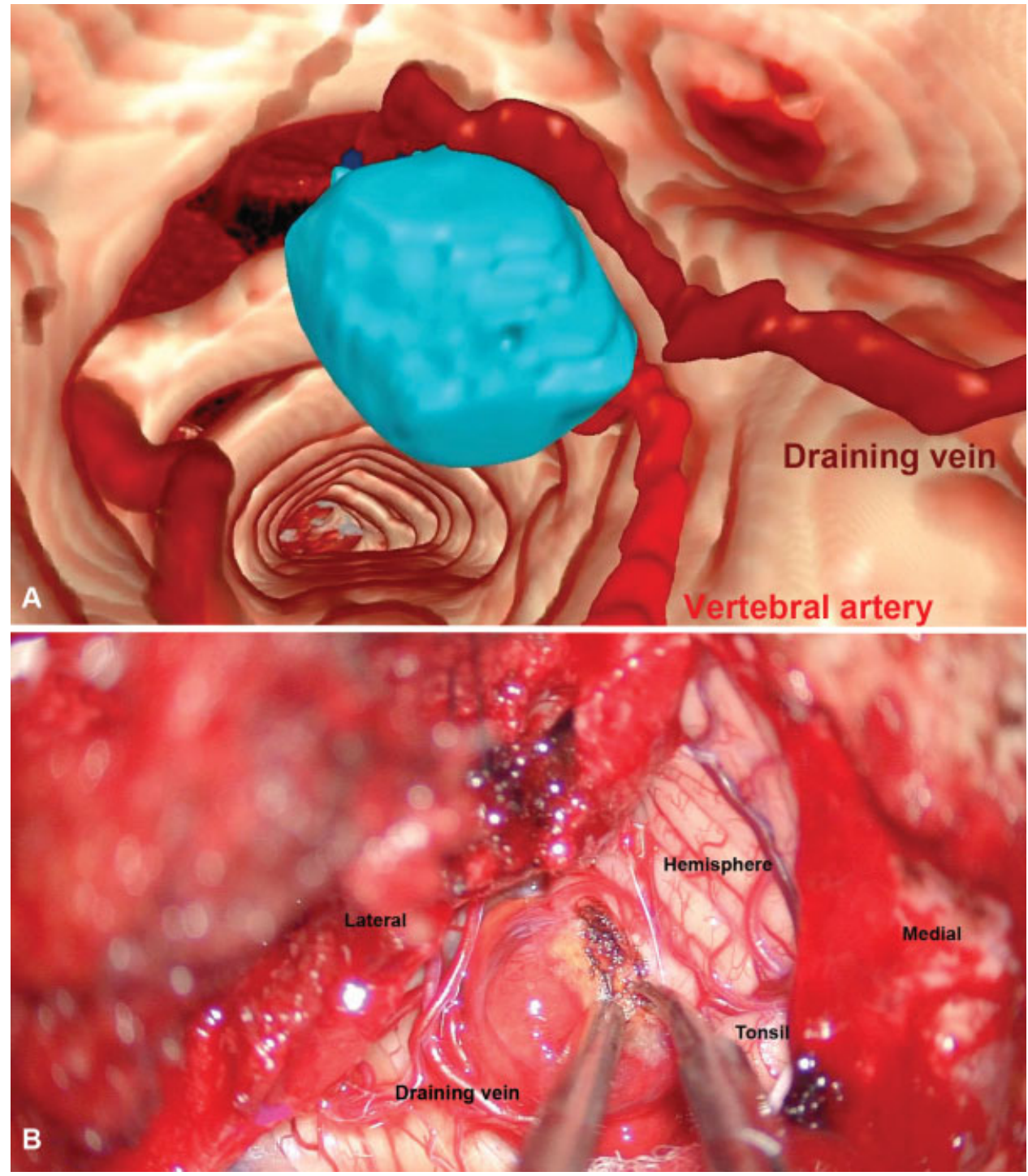

Fig. 2 Three-dimensional modeling and intraoperative images of craniocervical hemangioblastoma. (A) Using virtual reality software, a three-dimensional model of the lesion and associated cerebrovasculature was recreated. (B) intraoperative imaging demonstrates the relationship of anatomic structures to the lesion and the draining vein.

\section{Publication Comment}

The authors present a video of a patient with a craniocervical junction hemangioblastoma which was treated with a farlateraral retrocondilar approach. During this video the authors clearly exhibit the use of virtual reality to explain the adequate concepts of the surgical strategy. I commend the authors for the good result.

Diego Mendez Rosito, MD CMN 20 de Noviembre Mexico City, Mexico

\section{Disclosures}

None.

Conflict of Interest

None declared. 